\title{
Evaluation of Delayed Glyphosate Burndown in No-Till Soybean
}

\author{
Kimberly D. Belfry*, Christy Shropshire, Peter H. Sikkema \\ University of Guelph Ridgetown Campus, Ridgetown, Canada \\ Email: "kimberly.belfry@gmail.com
}

Received 27 February 2015; accepted 15 March 2015; published 20 March 2015

Copyright (C) 2015 by authors and Scientific Research Publishing Inc.

This work is licensed under the Creative Commons Attribution International License (CC BY). http://creativecommons.org/licenses/by/4.0/

(c) $\underset{\mathrm{EY}}{\mathrm{i}}$ Open Access

\begin{abstract}
Application of a preplant or preemergence glyphosate burndown is routine in most no-tillage production systems of annual crops, however, time of application may influence overall weed control and grain yield. Six field trials were conducted over a three-year period $(2008,2009$ and 2010) near Ridgetown, Ontario, Canada to determine the effect of glyphosate burndown application timing in glyphosate-resistant (GR) no-tillage soybean [Glycine max (L.) Merr.]. Soybean growth was reduced $5 \%, 10 \%$ and $20 \%$ when the burndown was delayed to 1,5 and 12 days after planting (DAP), when evaluated one week after application (WAA), respectively. By 8 WAA, predicted burndown timing increased to 9, 14 and 23 DAP, and was 10, 17 and 26 DAP at 12 WAA, to reduce soybean growth by $5 \%, 10 \%$ and $20 \%$, respectively. Similarly, burndown application at 14 , 21 and 30 DAP corresponded to a soybean yield reduction of $5 \%, 10 \%$ and $20 \%$. Seed moisture content was generally insensitive to burndown timing; 80 and 140 DAP were required to increase moisture by $5 \%$ and $10 \%$, respectively. This research indicates that delaying glyphosate burndown by up to 14 DAP, approximately VE to VC growth stage, has the potential to result in a modest reduction in soybean yield (5\%).
\end{abstract}

\section{Keywords}

Burndown, Glyphosate, Soybean

\section{Introduction}

With record production of nearly 6 million tonnes in 2014, soybean [Glycine max (L.) Merr.] continues to be Canada's most popular leguminous field crop [1]. Accounting for more than $60 \%$ of total Canadian production, Ontario soybean is valued at approximately 1.5 million dollars and typically occupies greater than 1 million hectares of crop land annually [2]. Soybean production has been met with continued growth over the past two

${ }^{*}$ Corresponding author. 
decades that has been attributed, in part, to the development of glyphosate-resistant (GR) cultivars and no-tillage production systems. Since introduction in 1997, adoption of GR soybeans has been rapid due to a relatively low cost, excellent crop safety and flexibility for subsequently planted crops [3] [4]. Furthermore, the simplicity of glyphosate application fits well into most weed management programs [5].

In Ontario, problem weeds frequently found in soybean fields include barnyard grass [Echinochloa crusgalli (L.) Beauv.], green foxtail [Setaria viridis (L.) Beauv.], common lambsquarters (Chenopodium album L.), velvetleaf (Abultilon theophrasti Medic.) and Canada thistle [Circium arvense (L.) Scop.] [6]. Glyphosate-based weed management, although efficacious, is often associated with conservation or no-tillage regimes which may hasten shifts in weed populations [7]. Examples include Canada fleabane (Conyza canadensis L.), giant ragweed (Ambrosia trifida L.) and common water hemp [Amaranthus tuberculatus (Moq ex DC) JD Sauer] [7]. Application of a preplant or preemergence herbicide, commonly referred to as a burndown, is the foundation of most weed control programs. For GR soybeans, glyphosate is generally a component of either applications, however, time of application has been shown to influence weed control and soybean yield [8] [9].

Traditionally, application of a burndown serves to control existing vegetation and prepare the field for soybean planting. Early application ensures effective control of winter annual, perennial and early emerging annual weeds. Weeds present at this time are generally in the juvenile growth stage or actively growing and thus more susceptible to control, however time constraints during this busy time of the season may prevent a punctual burndown application [6]. Alternatively, a delayed burndown may provide better control of later emerging annual weeds, assuming that the intensity of weeds does not negatively affect the newly emerging soybean crop. Reference [10] reported that the critical weed-free period in soybean is up to the fourth trifoliate (V4) growth stage and that weed interference occurring prior to the V4 stage may result in a yield loss of up to $2.5 \%$. However, reference [11] determined that the optimal time to apply glyphosate in GR soybean was approximately 18 to 28 days after planting, under conventional tillage.

Currently, most soybean growers apply a glyphosate burndown prior to or immediately following soybean planting. However, if glyphosate burndown can be delayed without penalty in soybean yield, it may provide growers with additional options and greater flexibility for early season weed control. The objectives of this study were to determine the number of days that glyphosate burndown may be delayed, relative to soybean planting, which result in a $5 \%, 10 \%$ and $20 \%$ reduction of soybean growth and yield as well a $5 \%$ and $10 \%$ increase in seed moisture based on a regression analysis, under Ontario field conditions.

\section{Materials and Methods}

\subsection{Study Establishment}

Six field trials were conducted over a three-year period (2008, 2009 and 2010) to determine the effect of delayed glyphosate burndown in GR soybeans. All trials were established at the University of Guelph, Ridgetown Campus near Ridgetown, Ontario, Canada $\left(42^{\circ} 26^{\prime} \mathrm{N}, 81^{\circ} 53^{\prime} \mathrm{W}\right)$. Ridgetown soils were analyzed each year prior to trial establishment and ranged from fine to very fine sandy loam in texture with sand, silt, clay and organic matter content of $63 \%$ to $79 \%, 12 \%$ to $19 \%, 9 \%$ to $18 \%$ and $6.4 \%$ to $6.9 \%$, respectively; soil $\mathrm{pH}$ ranged from 6.4 to 6.9 . All experiments were established in no-tillage production systems in the absence of irrigation.

The experimental design of this study was a randomized complete block with four replications. Herbicide treatments consisted of a weedy check and $1800 \mathrm{~g} \cdot \mathrm{ae}_{\mathrm{ha}} \mathrm{h}^{-1}$ glyphosate applied 2 weeks before planting (WBP), 1 WBP, 0 weeks after planting (WAP), 1 WAP, 2 WAP and 3 WAP. Soybeans were planted at a rate of approximately 400,000 seeds per hectare with a no-till planter in early May. Dates of herbicide application and soybean planting are listed in Table 1 . Seeds were planted to a depth of $3 \mathrm{~cm}$ in rows spaced $75 \mathrm{~cm}$ apart. Plots measured $3 \mathrm{~m}$ wide by $10 \mathrm{~m}$ long. Herbicide applications were made using a $\mathrm{CO}_{2}$-pressurized backpack sprayer calibrated to deliver $200 \mathrm{~L}$ aqueous solution per hectare at a pressure of $210 \mathrm{kPa}$. Boom length was $1.5 \mathrm{~m}$ with four "Ultralow drift" nozzles (ULD 120-02) spaced $50 \mathrm{~cm}$ apart. All herbicide applications were made in the absence of precipitation at a low-wind velocity to ensure maximum efficacy. To eliminate the confounding effects of postburndown weed interference each treatment, excluding the weedy check, was maintained free of weeds after the burndown application and for the remainder of the growing season.

\subsection{Data Collection}

Soybean growth was assessed on a scale of 1 to 10 , where 1 was defined as poor growth and 10 as ideal soybean 
Table 1. Soybean cultivar and dates of soybean planting and burndown application for experiments conducted near Ridgetown, Ontario from 2008 to $2010 .^{a}$

\begin{tabular}{cccccccccc}
\hline \multirow{2}{*}{ Environment } & \multirow{2}{*}{ Year } & \multirow{2}{*}{ Cultivar } & Planting & \multicolumn{5}{c}{ Burndown application timing } \\
\cline { 6 - 9 } & & & date & 2 WBP & 1 WBP & 0 WAP & 1 WAP & 2 WAP & 3 WAP \\
\hline S1 & 2008 & Dekalb 31-53 & May 29 & Apr. 29 & May 09 & May 29 & Jun. 5 & Jun. 11 & Jun. 19 \\
S2 & 2008 & Pioneer 30-07R & May 21 & May 6 & May 13 & May 23 & May 28 & Jun. 4 & Jun. 11 \\
S3 & 2009 & Dekalb 31-10RY & May 19 & May 5 & May 12 & May 20 & May 25 & Jun. 2 & Jun. 9 \\
S4 & 2009 & Dekalb 31-10RY & May 19 & May 5 & May 12 & May 20 & May 25 & Jun. 2 & Jun. 9 \\
S5 & 2010 & Dekalb 32-60RY & May 21 & May 6 & May 12 & May 26 & May 31 & Jun. 3 & Jun. 11 \\
S6 & 2010 & Dekalb 32-60RY & May 21 & May 6 & May 12 & May 26 & May 31 & Jun. 3 & Jun. 11 \\
\hline
\end{tabular}

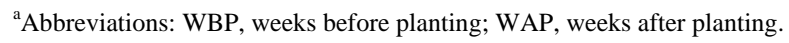

growth. Soybean growth was evaluated at 1, 4, 8 and 12 weeks after the last burndown application timing (3 WAP). Additionally, soybean growth stage was recorded per burndown timing, where plants were present (Table 2). Weed density per species was quantified at each burndown timing, however, for brevity only total density per environment, per timing were reported (Table 3). Soybean was harvested at maturity with a small plot combine. At harvest, weight and seed moisture were recorded; final yields were adjusted to $13 \%$ seed moisture content.

\subsection{Statistical Analysis}

Data were analyzed using non-linear regression (PROC NLIN) in SAS (Ver 9.2, Cary, NC). The weedy check was not included in the regression analysis. Soybean yield data were converted to a percent of the earliest burndown treatment (2 WBP). This treatment was chosen as it consistently rated 10 (ideal soybean growth) in all environments. All parameters were regressed against application timing in days after soybean planting (DAP). On the original scale, two treatments showed a negative DAP therefore all treatments were adjusted by 30 DAP to ensure all numbers were positive; a requirement for a log-logistic model. Following calculation of predicted values, 30 days was then subtracted from each treatment to convert data back to the original scale.

Growth ratings and yield (DAP-response) were determined using a four parameter log-logistic model:

$$
Y=C+D-C /\left(1+\exp \left[-b\left(\ln \mathrm{DAP}-\ln \mathrm{I}_{50}\right)\right]\right)
$$

where $C$ is the lower asymptote, $D$ is the upper asymptote, $b$ is the slope and $\mathrm{I}_{50}$ is the application timing which gives a response halfway between $C$ and $D$ [12].

Soybean percent moisture content at harvest was determined using a segmented linear regression:

$$
\begin{aligned}
& Y_{L}=a_{0}+b_{1} * \text { DAP } \\
& Y_{R}=a_{0}+b_{1} * j+b r_{1} *(\mathrm{DAP}-j)
\end{aligned}
$$

where $Y_{L}$ and $Y_{R}$ are the left and right segments, respectively, $a_{0}$ is the left intercept, $b_{1}$ is the slope of the left segment, $b r_{1}$ is the slope of the right segment and $j$ is the junction point of the two segments [13].

Regression equations used to calculate predicted burndown application timing (in DAP) that resulted in a 5\%, $10 \%$ and $20 \%$ reduction $\left(\mathrm{R}_{5}, \mathrm{R}_{10}\right.$ and $\mathrm{R}_{20}$, respectively) in soybean growth and yield, as well as DAP resulting in a $5 \%$ and $10 \%$ increase ( $I_{5}$ and $I_{10}$, respectively) in soybean moisture content at harvest. If the predicted burndown application timing was outside the range of days (from the first application to harvest), it was expressed as a missing data point.

\section{Results and Discussion}

No significant environment by treatment interaction was detected therefore all data from each environment for each variable was pooled. Timing of burndown did not generally impact soybean seed moisture content. According to the analysis, a delay of 80 and 140 DAP would be required to increase soybean moisture by $5 \%$ and $10 \%$, respectively (data not shown). 
Table 2. Dates of soybean planting, emergence and growth stage 0, 1, 2 and 3 WAP for experiments conducted near Ridgetown, Ontario from 2008 to 2010. ${ }^{a}$

\begin{tabular}{cccccccc}
\hline \multirow{2}{*}{ Environment } & Year & Planting date & Emergence & \multicolumn{4}{c}{ Soybean growth stage } \\
\cline { 6 - 8 } & & date & 0 WAP & 1 WAP & 2 WAP & 3 WAP \\
S1 & 2008 & May 29 & Jun. 8 & - & VE & VC & V1 \\
S2 & 2008 & May 21 & Jun. 6 & - & - & VE & VC \\
S3 & 2009 & May 19 & May 26 & - & VE & VC & V1 \\
S4 & 2009 & May 19 & May 26 & - & VE & VC & V1 \\
S5 & 2010 & May 21 & May 28 & - & - & VE & VC \\
S6 & 2010 & May 21 & May 28 & - & - & VE & VC \\
\hline
\end{tabular}

${ }^{\mathrm{a}}$ Abbreviations: WAP, weeks after planting.

Table 3. Weed density per burndown timing for experiments conducted near Ridgetown, Ontario from 2008 to 2010 . $^{\text {a }}$

\begin{tabular}{|c|c|c|c|c|c|c|c|c|}
\hline \multirow{2}{*}{ Environment } & \multirow{2}{*}{ Year } & \multirow{2}{*}{ Planting date } & \multicolumn{6}{|c|}{ Burndown timing $^{\mathrm{b}}$ (weeds $\cdot \mathrm{m}^{-2}$ ) } \\
\hline & & & $2 \mathrm{WBP}$ & $1 \mathrm{WBP}$ & 0 WAP & $1 \mathrm{WAP}$ & 2 WAP & 3 WAP \\
\hline $\mathrm{S} 1$ & 2008 & May 29 & 2004 & 2273 & 1089 & 1348 & 1506 & 1181 \\
\hline $\mathrm{S} 2$ & 2008 & May 21 & 70 & 84 & 52 & 21 & 36 & 31 \\
\hline S3 & 2009 & May 19 & 30 & 14 & 29 & 29 & 134 & 140 \\
\hline S4 & 2009 & May 19 & 28 & 50 & 38 & 40 & 29 & 35 \\
\hline S5 & 2010 & May 21 & 78 & 90 & 99 & 98 & 107 & 71 \\
\hline S6 & 2010 & May 21 & 151 & 123 & 141 & 131 & 154 & 127 \\
\hline
\end{tabular}

${ }^{\mathrm{a}}$ Abbreviations: WBP, weeks before planting; WAP, weeks after planting. ${ }^{\mathrm{b}}$ Weeds present included: Abutilon theophrasti, Ambrosia artemisiifolia, Bromus tectorum, Chenopodium album, Conyza canadensis, Daucus carota, Lactuca serriola, Panicum dichotoflorum, Setaria faberi, Stellaria media and Triticum aestivum.

At 1 WAA, burndown applications at 1, 5 and 12 DAP were predicted to reduce soybean growth by $5 \%, 10 \%$ and $20 \%$, respectively (Table 4). By 8 WAA, predicted burndown timings for $R_{5}, R_{10}$ and $R_{20}$ doubled and were 9, 14 and 23 DAP, respectively. Burndown applications remained relatively constant for 12 WAA and were 10, 17 and 26 DAP for the same reductions, respectively. The results of this study indicate that despite soybean growth being sensitive to burndown 1 WAA, the lasting effects on soybean growth became diminished over time, evident by declining slope $(b)$ values from 1 to 12 WAA. Furthermore, the predicted delay in burndown required to reduce soybean yield by $5 \%, 10 \%$ and $20 \%$ was 14,21 and 30 DAP, respectively. This study evaluated soybean growth and yield in response to burndown timing in the absence of post-burndown weeds, thus suggesting that any reduction in growth or yield be attributed to early season weed interference prior to the burndown application (Table 3). Therefore, based on this study, a grower who delays glyphosate burndown to 14 DAP, at approximately the cotyledon (VC) to unifoliate (VE) growth stage, would incur a yield reduction of 5\% solely from delayed burndown applicaiton (Table 2 and Table 4).

In other studies, reference [14] reported variable GR soybean yield in response to timing of glyphosate application (cracking to V7), but reported consistently high yields for V2 to V4 treatments that were paired with a preplant burndown. In a related study, reference [15] evaluated the role of delayed burndown in GR corn (Zea mays L.) planted into a wheat (Triticum aestevum L.) cover crop and found that increasing DAP significantly reduced corn height, relative to the weed-free control. However, for treatments not planted into a cover crop, weed control increased (up to 28\%) as the burndown application timing was delayed; when accompanied with a sequential glyphosate application weed control increased to $90 \%$. The latter implies that while there may be an inherent benefit to delaying burndown, a single glyphosate application is not likely to be sufficient for season-long weed control [11] [16]. This is further supported by existing research that reports that the critical time of weed removal in soybean is between the vegetative and early reproductive growth stages; and a delay in burndown is not recommended in these studies [10] [17] [18]. Similarly, a related survey assessed perceptions 
Table 4. Regression parameter estimates and predicted burndown application timings from dose (DAP)-response models of soybean growth ratings and yield. ${ }^{a}$

\begin{tabular}{|c|c|c|c|c|c|c|c|c|c|c|c|c|}
\hline \multirow{3}{*}{$\begin{array}{c}\text { Variable } \\
\text { Growth rating }\end{array}$} & \multirow{3}{*}{$\begin{array}{c}\text { WAA } \\
1\end{array}$} & \multicolumn{8}{|c|}{ Parameter estimates $^{\mathrm{b}}( \pm \mathrm{SE})$} & \multicolumn{3}{|c|}{$\begin{array}{l}\text { Predicted burndown timing } \\
\text { (DAP) }{ }^{\mathrm{c}}\end{array}$} \\
\hline & & \multicolumn{2}{|c|}{ C } & \multicolumn{2}{|c|}{$D$} & \multicolumn{2}{|c|}{$b$} & \multicolumn{2}{|c|}{$\mathrm{I}_{50}$} & \multirow{2}{*}{$\begin{array}{c}\mathrm{R}_{5} \\
1\end{array}$} & \multirow{2}{*}{$\begin{array}{c}\mathrm{R}_{10} \\
5\end{array}$} & \multirow{2}{*}{$\begin{array}{c}\mathrm{R}_{20} \\
12\end{array}$} \\
\hline & & 7.1 & $(0.2)$ & 10.0 & $(0.2)$ & 7.8 & $(2.5)$ & 38 & $(2)$ & & & \\
\hline & 4 & 6.2 & $(0.3)$ & 10.0 & $(0.0)$ & 5.7 & $(1.2)$ & 44 & (2) & 1 & 6 & 15 \\
\hline & 8 & 5.6 & $(0.2)$ & 10.0 & $(0.0)$ & 5.9 & (1.4) & 55 & (3) & 9 & 14 & 23 \\
\hline & 12 & 4.6 & $(0.2)$ & 10.0 & $(0.0)$ & 5.4 & (1.4) & 62 & (5) & 10 & 17 & 26 \\
\hline Yield & & 29.3 & $(4.4)$ & 99.8 & $(2.2)$ & 5.2 & (3.9) & 72 & (20) & 14 & 21 & 30 \\
\hline
\end{tabular}

${ }^{\mathrm{a}}$ Abbreviations: DAP, days after soybean planting; WAA, weeks after the final burndown application. ${ }^{\mathrm{b}}$ Dose response parameters (Equation (1)): $b$, slope; $C$, lower asymptote; $D$, upper asymptote; $I_{50}$, burndown application timing in DAT that gives a $50 \%$ response. ${ }^{c} R_{5}$, $R_{10}$, and $R_{20}$ are the $D_{A P}$ that result in 5\%, $10 \%$ and $20 \%$ reduction in soybean growth or yield.

about the importance of weed control timing for Indiana soybean growers [19]. The survey found that despite the perceived importance of planting into a clean field, almost a third of the growers surveyed did not feel a compelling need to do so. The survey concluded that weed size and density were the most common criteria when determining when to spray, suggesting that crop scouting plays a substantial role in the decision-making process.

\section{Conclusion}

In summary, application of glyphosate up to $14 \mathrm{DAP}$, at about the VE to VC growth stage, may reduce soybean growth and yield up to $10 \%$ and $5 \%$, respectively. However, timing of application does not appear to impact soybean seed moisture content. This study evaluated the impact of delayed burndown in the absence of weed interference post-burndown and thus all soybean growth and yield predictions made are attributed primarily to the impact of early-season weed interference. Consequently, the implementation of a postemergence weed control application will most likely be required to ensure season-long control. Future research should consider the implications of delayed burndown on weed control and if the perceived benefit to delaying burndown brings about a reduction in control.

\section{Acknowledgements}

The authors would like to acknowledge Christy Shropshire and Lynette Brown for the execution of field trials. This research was made possible through funding from the Grain Farmers of Ontario.

\section{References}

[1] Statistics Canada (2014) Production of Principle Field Crops, September 2014. http://www.statcan.gc.ca/daily-quotidien/141003/dq141003b-eng.htm

[2] Kulasekera, K. (2014) Estimated Area, Yield, Production and Farm Value of Specified Field Crops, Ontario, 20112013. Ontario Ministry of Agriculture, Food and Rural Affairs. http://www.omafra.gov.on.ca/english/stats/crops/estimate new.htm

[3] Beckie, H.J. (2006) Herbicide-Resistant Weeds: Management Tactics and Practices. Weed Technology, 20, $793-814$. http://dx.doi.org/10.1614/WT-05-084R1.1

[4] Duke, S.O. and Powles, S.B. (2008) Glyphosate: A Once-in-a-Century Herbicide. Pest Management Science, 64, 319325. http://dx.doi.org/10.1002/ps.1518

[5] Beckie, H.J., et al. (2006) A Decade of Herbicide-Resistant Crops in Canada. Canadian Journal of Plant Science, 86, 1243-1264. http://dx.doi.org/10.4141/P05-193

[6] Ontario Ministry of Agriculture, Food and Rural Affairs (OMAFRA) (2013) Guide to Weed Control 2014-2015: Publication 75. Queen's Printer for Ontario, Toronto.

[7] Owen, M.D. (2008) Weed Species Shifts in Glyphosate-Resistant Crops. Pest Management Science, 64, 377-387. 
http://dx.doi.org/10.1002/ps.1539

[8] Marra, M.C., Piggott, N.E. and Carlson, G.A. (2004) The Net Benefits, Including Convenience, of Roundup Ready ${ }^{\circledR}$ Soybeans: Results from a National Survey, Technical Bulletin 2004-3. NSF Center for Integrated Pest Management, Ralieigh.

[9] Gonzini, L.C., Hart, S.E. and Wax, L.M. (1999) Herbicide Combinations for Weed Management in Glyphosate- Resistant Soybean (Glycinemax). Weed Technology, 13, 354-360.

[10] Van Acker, R.C., Swanton, C.J. and Weise, S.F. (1993) The Critical Period of Weed Control in Soybean [Glycinemax (L.) Merr.], Weed Science, 41, 194-200.

[11] Vangessel, M.J., Ayeni, A.O. and Majek, B.A. (2000) Optimum Glyphosate Timing with or without Residual Herbicides in Glyphosate-Resistant Soybean (Glycine max) under Full-Season Conventional Tillage, Weed Technology, 14, 140-149. http://dx.doi.org/10.1614/0890-037X(2000)014[0140:OGTWOW]2.0.CO;2

[12] Seefeldt, S.S., Jensen, J.E. and Fuerst, E.P. (1995) Log-Logistic Analysis of Herbicide Dose-Response Relationships. Weed Technology, 9, 218-227.

[13] Bowley, S. (1999) A Hitchhiker’s Guide to Statistics in Plant Biology. AnyOldSubjectBooks, Guelph.

[14] Vangessel, M.J., Ayeni, A.O. and Majek, B.A. (2001) Glyphosate in Full-Season No-Till Glyphosate-Resistant Soybean: Role of Preplant Applications and Residual Herbicides. Weed Technology, 15, 714-724. http://dx.doi.org/10.1614/0890-037X(2001)015[0714:GIFSNT]2.0.CO;2

[15] Tharp, B.E. and Kells, J.J. (2001) Delayed Burndown in No-Tillage Glyphosate-Resistant Corn (Zea mays) Planted into Soybean (Glycine max) Residue and a Wheat (Triticum aestivum) Cover Crop. Weed Technology, 15, 467-473. http://dx.doi.org/10.1614/0890-037X(2001)015[0467:DBINTG]2.0.CO;2

[16] Cox, W.J., Hahn, R. and Stachowski, P.J. (2006) Time of Weed Removal with Glyphosate Affects Corn Growth and Yield Components. Agronomy Journal, 98, 349-353. http://dx.doi.org/10.2134/agronj2005.0078

[17] Mulugeta, D. and Boerboom, C.M. (2000) Critical Time of Weed Removal in Glyphosate-Resistant Glycinemax. Weed Science, 48, 35-42. http://dx.doi.org/10.1614/0043-1745(2000)048[0035:CTOWRI]2.0.CO;2

[18] Swanton, C.J., Shrestha, A., Chandler, K. and Deen, W. (2000) An Economic Assessment of Weed Control Strategies in No-Till Glyphosate-Resistant Soybean (Glycinemax). Weed Technology, 14, 755-763. http://dx.doi.org/10.1614/0890-037X(2000)014[0755:AEAOWC]2.0.CO;2

[19] Johnson, W.G., Gibson, K.D. and Conley, S.P. (2007) Does Weed Size Matter? An Indiana Grower Perspective about Weed Control Timing. Weed Technology, 21, 542-546. http://dx.doi.org/10.1614/WT-06-094R.1 